\title{
SISTEM INFORMASI PEMESANAN JASA ONLINE BERBASIS WEB STUDI KASUS KABUPATEN JOMBANG
}

\author{
Wahyu Aji Tri Riswandhana *) Primaadi Airlangga \\ *Program Studi Informatika Universitas KH. A. Wahab Hasbullah \\ Correspondence Author: wahyu.aji.tri.riswandhana@gmail.com
}

\begin{tabular}{|c|c|}
\hline tikel : & ABSTRAK \\
\hline $\begin{array}{l}\text { Keywords: } \\
\text { Systems, Information, } \\
\text { Reservations, Services } \\
\text { Online }\end{array}$ & $\begin{array}{l}\text { One of the causes of high unemployment is because job seekers only focus } \\
\text { on looking for work without realizing the opportunities around them while } \\
\text { electronic equipment, household activities, and transportation are } \\
\text { secondary needs in daily life, which are complementary to basic needs or } \\
\text { needs. primary. When it is damaged or there is no free time to fix it, it will } \\
\text { disrupt daily activities. These things require a technician to repair and } \\
\text { run them, moreover, many people have expertise in these fields but have } \\
\text { not had jobs because of the company's high qualifications. Therefore a } \\
\text { system design is needed that can facilitate the search for technical } \\
\text { services as well as a place for people who have expertise in their fields. So } \\
\text { from these problems, a system is designed that is useful as a place or } \\
\text { container for ordering services and service providers to find and channel } \\
\text { their expertise. }\end{array}$ \\
\hline
\end{tabular}

Kata Kunci :

Sistem, Informasi,

Pemesanan, Jasa,

Online

\section{INTISARI}

Salah satu penyebab tingginya angka pengangguran adalah karena para pencari kerja hanya fokus pada mencari kerja tanpa menyadari peluang yang ada di sekeliling mereka sedangkan peralatan elektronik, kegiatan rumah tangga, dan transportasi merupakan kebutuhan sekunder dalam kehidupan sehari-hari, yang merupakan pelengkap kebutuhan pokok atau kebutuhan primer. Pada saat hal tersebut mengalami kerusakan atau tidak adanya waktu luang untuk memperbaiki hal tersebut, maka akan menggangu kegiatan sehari-hari. Hal-hal tersebut membutuhkan seorang teknisi untuk memperbaiki maupun menjalankanya, terlebih lagi banyak masyarakat yang memiliki keahlian dalam bidang-bidang tersebut namun belum meliliki pekerjaan karena kualifikasi perusahaan yang tinggi. Oleh karena itu diperlukan perancangan sistem yang dapat memudahkan dalam pencarian jasa teknisi serta sebagai wadah bagi masyarakat yang memiliki keahlian di bidangnya. Maka dari permasalahan tersebut dirancangkan sistem yang berguna sebagai tempat atau wadah bagi pemesanan jasa maupun penyedia jasa untuk mencari serta menyalurkan keahlianya.

\section{PENDAHULUAN}

Pengangguran adalah salah satu masalah nasional yang tidak mudah untuk dicari penyelesaianya. Salah satu contohnya yaitu kabupaten Jombang Jawa Timur, Jumlah pengangguran di Kabupaten Jombang, pada tahun ini meningkat jika dibanding tahun lalu. Berdasarkan hasil pendataan Dinas Sosial, Ketenagakerjaan dan Trasmigrasi, hingga bulan Oktober ini jumlah pencari kerja mencapai 13.066 orang. Sedangkan angka pengangguranya mencapai 57.899 orang. ${ }^{1}$

Salah satu penyebab tingginya angka pengangguran adalah karena para pencari kerja hanya fokus pada mencari kerja tanpa menyadari peluang yang ada di sekeliling mereka. Tanpa

${ }^{1}$ TEMPO.CO ; “Angka Pengangguran di Jombang Meningkat” https://nasional.tempo.co/read/209771/angkapengangguran-di-jombang-meningkat : 26 November 2017 
harus bekerja pada perusahaan sebenarnya peluang kerja dapat dilihat dibanyak tempat seperti sekolah-sekolah yang membutuhkan tenaga pengecatan interior dan exterior masjid-masjid yang membutuhkan teks berjalan.

Pada penelitian sebelumnya (Yogi, Rezal Renandha Prapta. 2017) telah dikaji bagaimana membangun sebuah Pemesanan Jasa Berbasis Web. Pada penelitian tersebut dihasilkan sebuah sistem informasi berbasis web yang dapat memesan jasa melalui website akan tetapi masih banyak kekurangan, salah satu diantaranya adalah barang yang akan di servis harus dikirim ke tempat penyedia jasa terlebih dahulu sedangkan website yang akan dibangun dalam penelitian ini , pemesan jasa cukup menunggu di rumah dan penyedia jasa akan datang ke tempat pemesan jasa tersebut. Selain itu pembayaran bisa dilakukan dan nego secara langsung.

Dengan melihat latar belakang, serta permasalahan yang ada, maka Penulis mengambil judul "Perancangan Aplikasi Pemesanan Jasa Online berbasis web, Studi Kasus Wilayah Kabupaten Jombang"

\section{METODOLOGI}

\subsection{Alat dan Bahan}

Dalam melakukan penelitian ini, alat yang digunakan untuk keberhasilan penelitian adalah sebagai berikut :

a. Kebutuhan Perangkat Keras

Perangkat keras yang dibutuhkan untuk implementasi dan pengembangan sistem adalah satu unit computer meliputi monitor, keyboard, mouse, motherboard,harddisk, CPU casing, dan modem GSM. Untuk lebih jelasnya berikut spesifikasi perangkat keras yang direkomendasikan:

\begin{tabular}{|l|l|}
\hline \multicolumn{1}{|c|}{ Pengembangan } & \multicolumn{1}{|c|}{ Implementasi } \\
\hline $\begin{array}{l}\text { 1. } \text { Prosesor minimal intel dual } \\
\text { core } 2,1 \mathrm{GHz}\end{array}$ & $\begin{array}{l}\text { 1. } \text { Prosesor minimal intel } \\
\text { dual core } 2,1 \mathrm{GHz}\end{array}$ \\
2. RAM minimal $2 \mathrm{~GB}$. & 2. RAM minimal $1 \mathrm{~GB}$. \\
3. Hard disk $250 \mathrm{~GB}$ & 3. Hard disk $250 \mathrm{~GB}$ \\
4. Modem Huawei 173. & 4. Modem Huawei 173. \\
5. SIM Card & 5. SIM Card \\
6. Mouse & 6. Mouse \\
7. Keyboard. & 7. Keyboard. \\
\hline
\end{tabular}

Tabel 2. Perangkat Keras Untuk Proses Pengembangan dan Implementasi Sistem.

b. Kebutuhan Perangkat Lunak

Kebutuhan perangkat lunak untuk proses pengembangan sistem ini adalah sebagai berikut :

1. Sistem operasi yang digunakan untuk membuat aplikasi ini adalah windows 7 .

2. Notepad ++ 6.3 untuk area kerja coding pembuatan apikasi .

3. Apache web server (XAMPP 1.7.1) untuk testing hasil kerja coding.

4. mySQL 5.1.30 digunakan untuk membuat database yang berfunsi untuk menyimpan database.

Sedangkan untuk implementasi sistem, perangkat lunak yang dibutuhkan adalah sebagai berikut :

1. Sistem operasi windows XP/7/8/10, Linux dan Mac OS

2. Web browser, yang digunakan untuk mengakses website e-jasa.

\subsection{Prosedur Penelitian}

Penelitian ini merupakan penelitian untuk memudahkan dalam memesan jasa secara online dan real time. Metode penelitian untuk menyelesaikan permasalahan ini adalah sebagai berikut:

1. Studi literatur,

2. Pengumpulan data, Data yang dikumpulkan antara lain diperoleh dari masyarakat umum. 
3. PEMBAHASAN

3.1 Perancangan Sistem

a. DFD

DFD dalam sebuah progam dimana konsumen atau member akan melakukan pemilihan jasa sesuai kebutuhan.

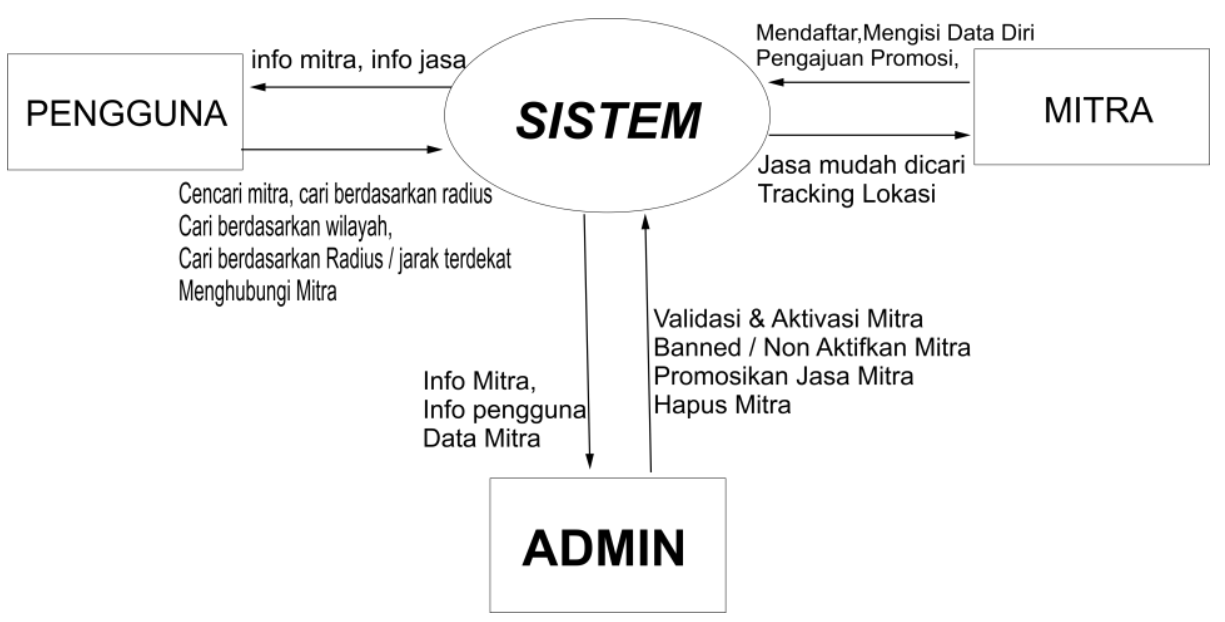

Gambar 3. Gambar Data Flow Diagram

b. Flowchart

Adapun tahap-tahap pemesan jasa dalam melakukan pemesanan jasa dimana pengguna mulai dengan memilih jasa kemudian lihat detail jasa dan kemudian bisa langsung menghubungi penyedia jasa. Adapaun flowchart dari sistem e-jasa adalah sebagai berikut.

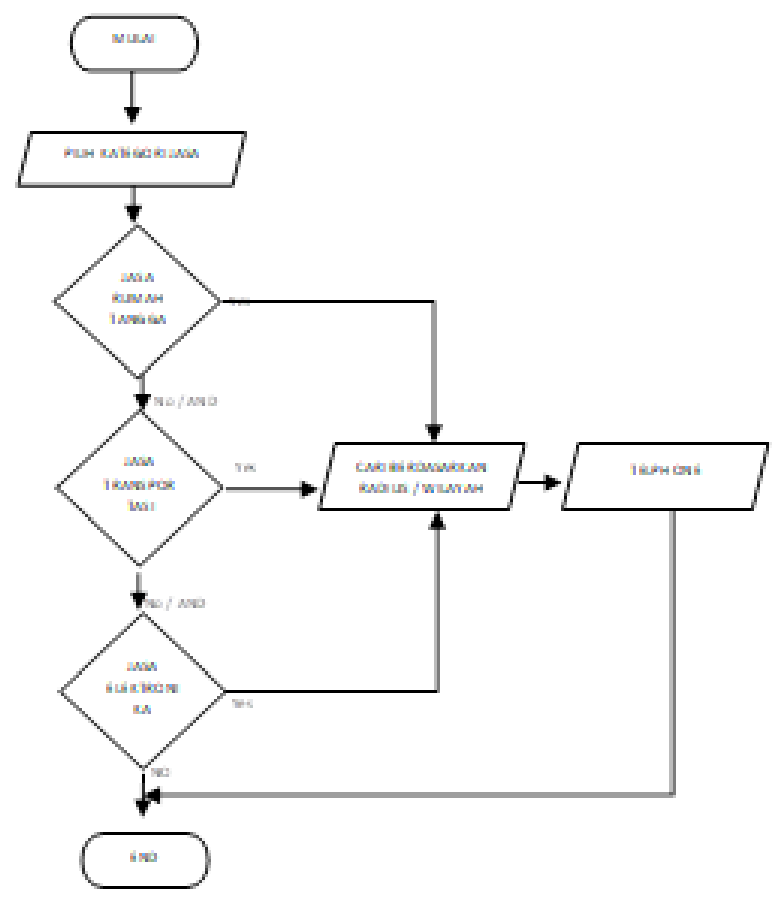

Gambar 4. Gambar Flowchat

\subsection{Perancangan Interfase Aplikasi}

Dibagian ini akan membahas terkait segi rancangan tampilan dari setiap antarmuka yang terdapat di dalam website pemesanan jasa tersebut. 
Antarmuka tersebut diuraikan sebagaimana berikut.

a. Halaman awal e-jasa jasa dibuka.

Halaman Awal adalah halaman awal yang akan muncul pertama kali saat web e-

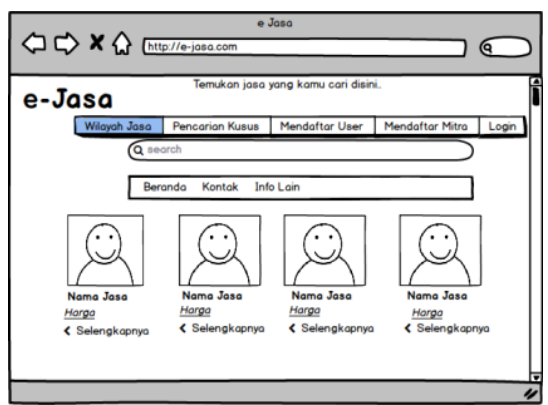

Gambar 5. Tampilan Halaman Awal e-jasa

b. Halaman Mendaftar Mitra

Halaman mendaftar mitra adalah halaman yang digunakan mitra untuk daftar secara online .

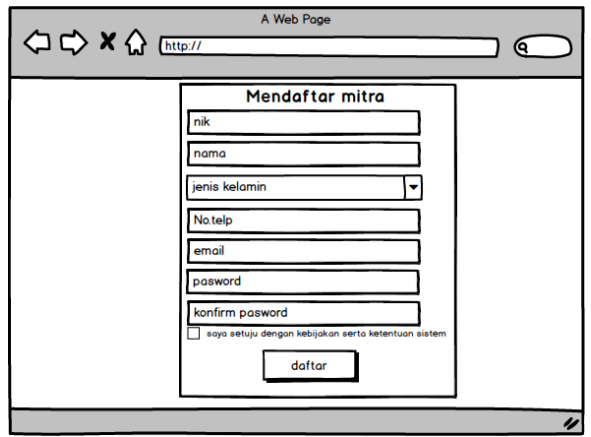

Gambar 6. Tampilan Halaman Mendaftar Mitra

c. Halaman Mendaftar User

Halaman mendaftar user digunakan untuk user mendaftar ke user.

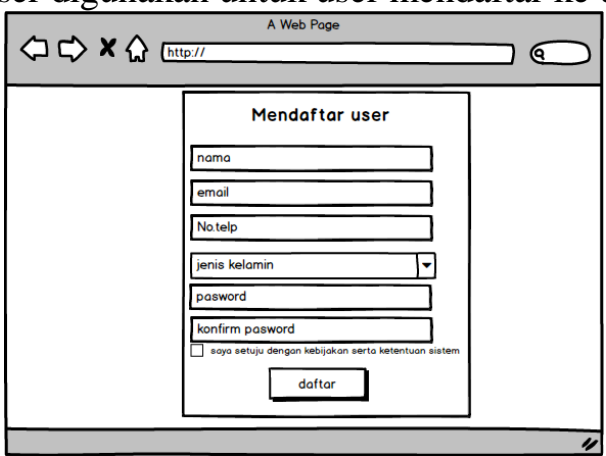

Gambar 7. Tampilan Halaman Mendaftar User

d. Halaman Pencarian Berdasarkan Wilayah

Halaman pencarian berdasarkan wilayah adalah pencarian yang didasarkan kategori jasa tertentu untuk mencari jasa pada wilayah tertentu. 


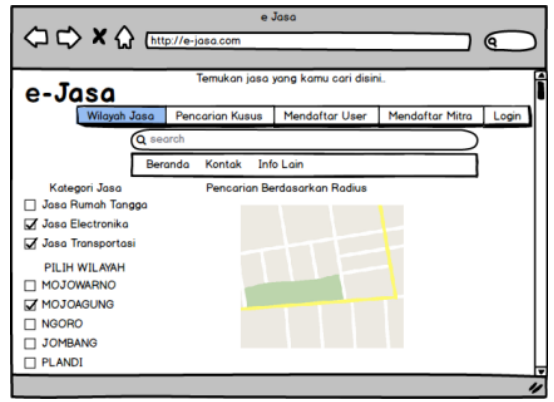

Gambar 8. Tampilan Halaman Pencarian Berdasarkan Wilayah.

e. Halaman Pencarian Berdasarkan Radius

Pencarian berdasarkan radius adalah mencari kategori jasa dalam radius atau jarak tertentu.

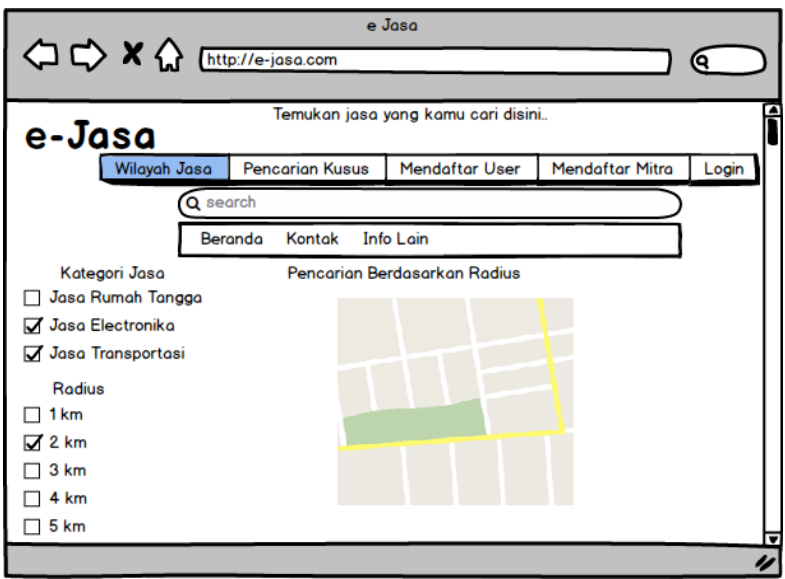

Gambar 9. Tampilan Halaman Pencarian Berdasarkan Radius

f. Halaman Login

Halaman login merupakan halaman yang digunakan untuk mitra maupun user login ke sistem.

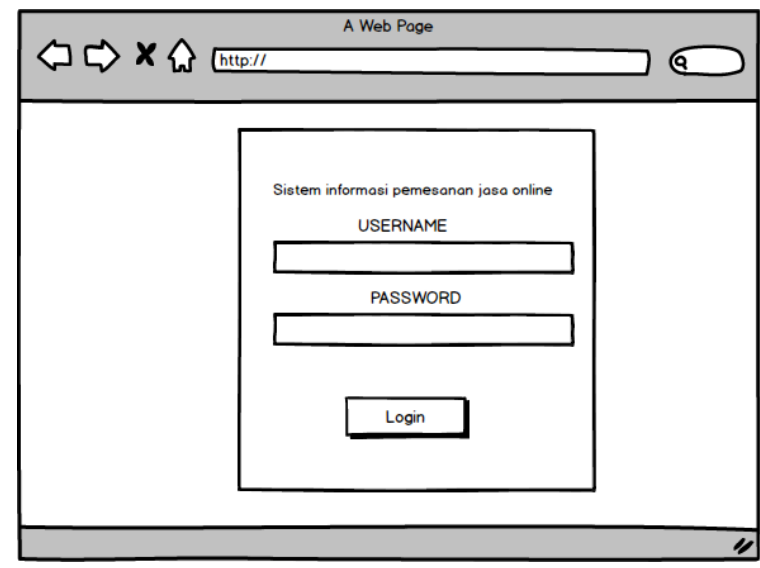

Gambar 10. Tampilan Halaman Login

g. Halaman Beranda Admin

Pada halaman ini digunakan admin mengetahui semua data baik menambah, mengedit dan mengedit mitra. 


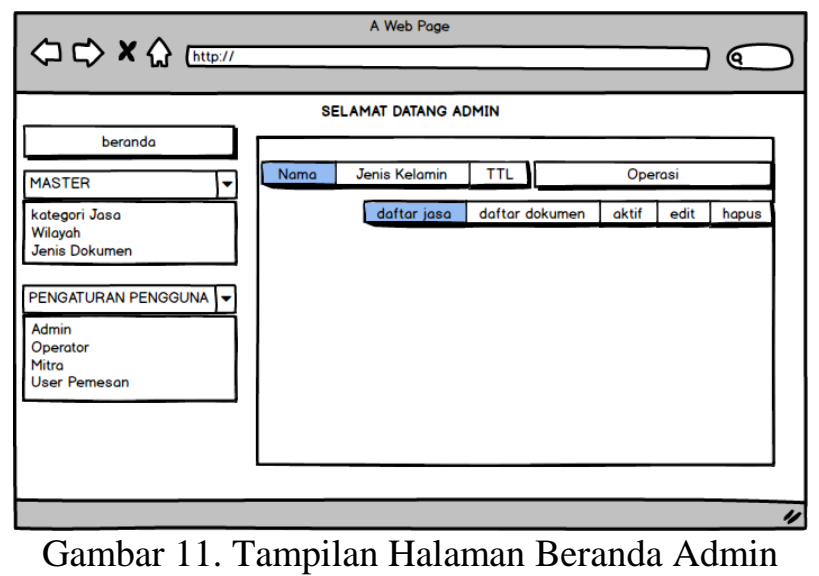

h. Halaman Beranda Mitra

Halaman ini digunakan mitra untuk menambah jasa dan dokumen mitra tersebut.

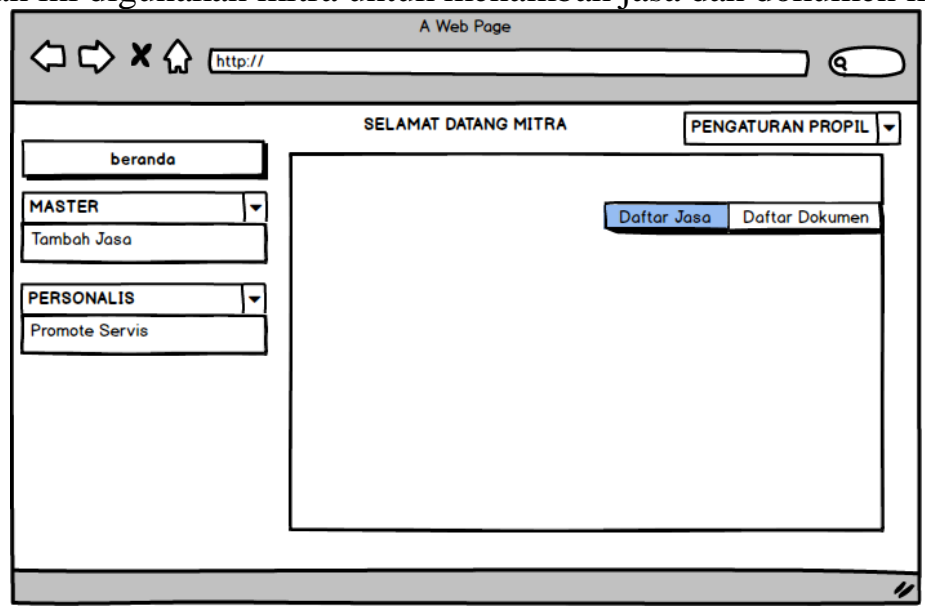

Gambar 12. Tampilan Halaman Beranda User

i. Halaman Detail Jasa

Halaman detail jasa untuk melihat secara detail jasa yang dipilih, mulai nama pemilik, nomor telepon, deskripsi dan alamat.

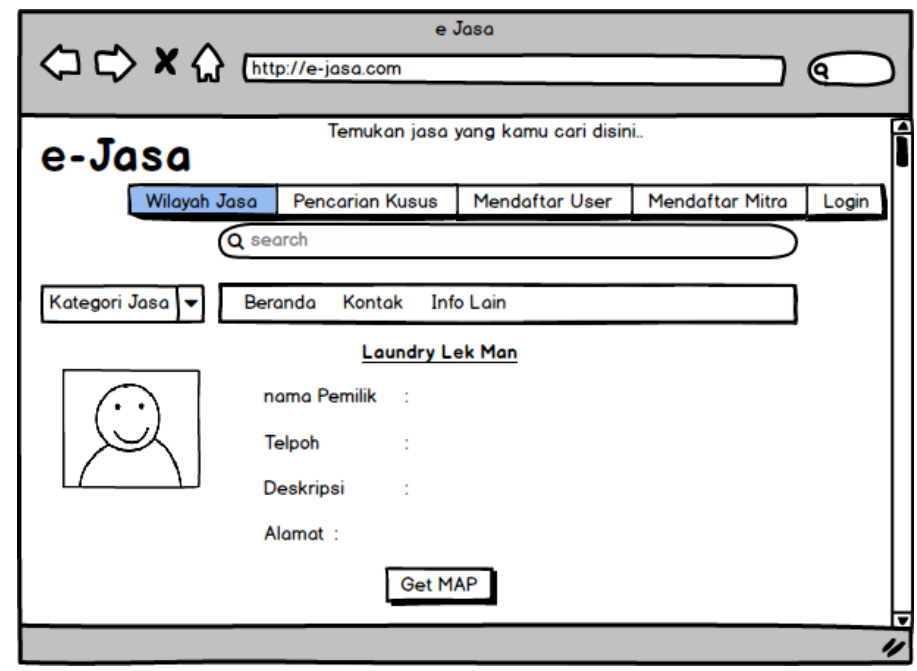

Gambar 13. Tampilan Halaman Detail Jasa 


\subsection{Hasil Interface Aplikasi}

Setelah dilakukan perancangan interface, dilakukan pengujian untuk melihat apakah hasil perancangan dapat berjalan sesuai harapan. Adapun sebagian hasil yang didapatkan adalah sebagai berikut :

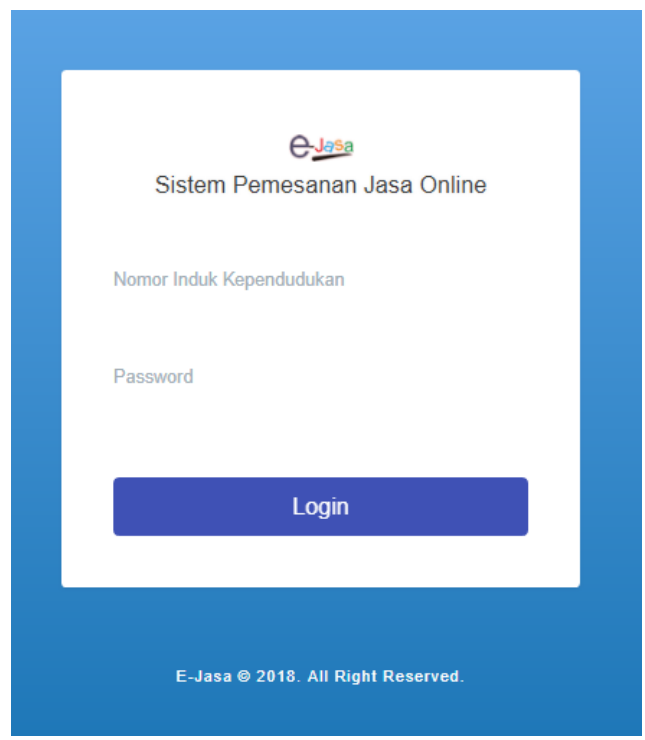

Gambar 14. Halaman Login

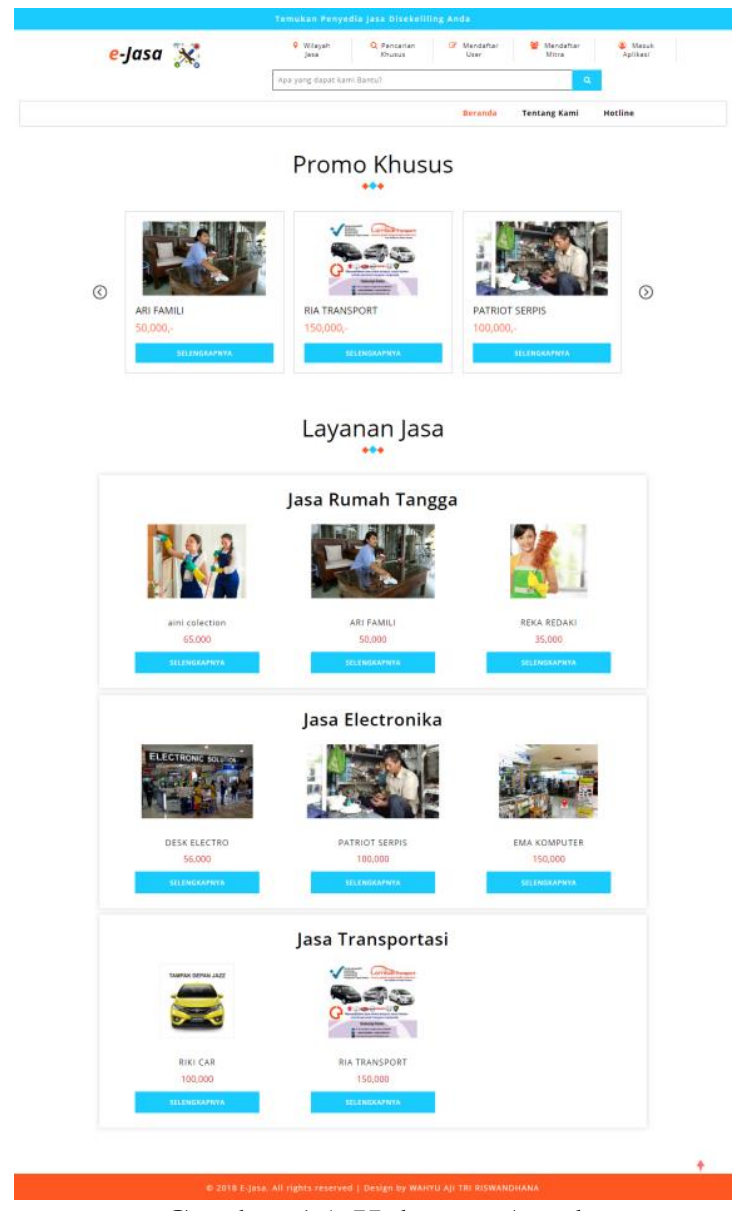

Gambar 15. Halaman Awal 

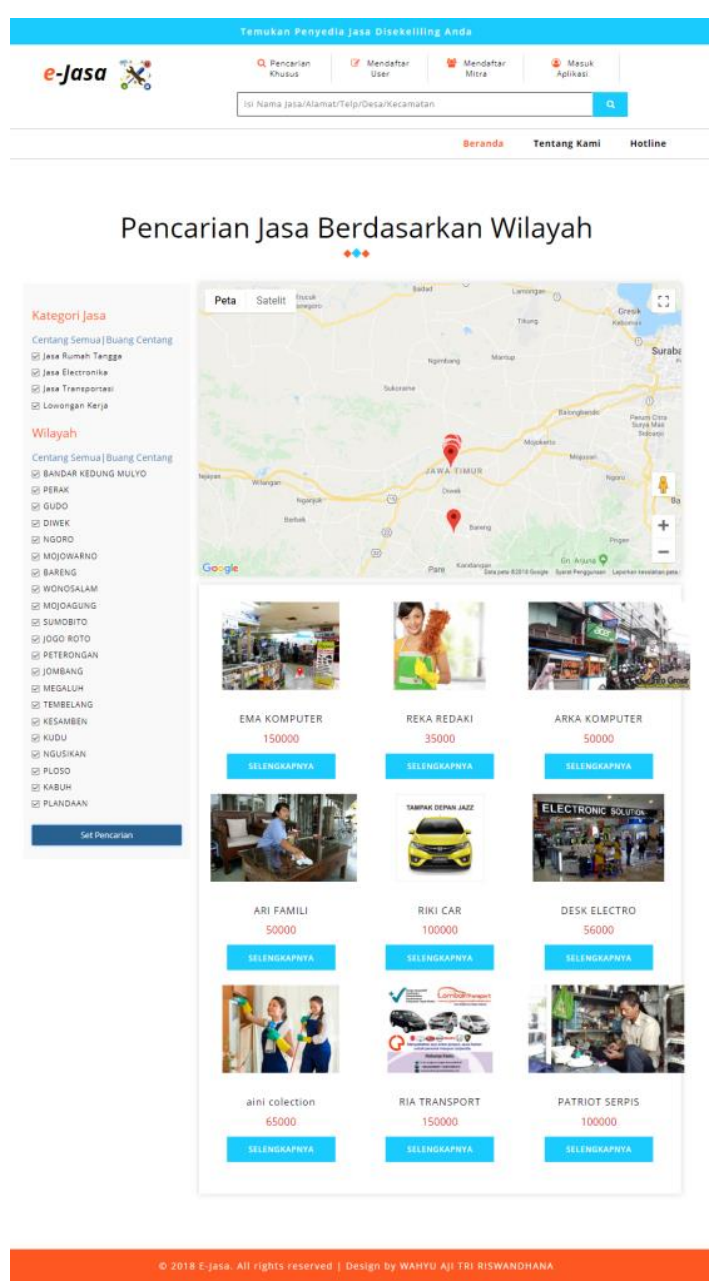

Gambar 16. Halaman Pencarian Berdasarkan Wilayah

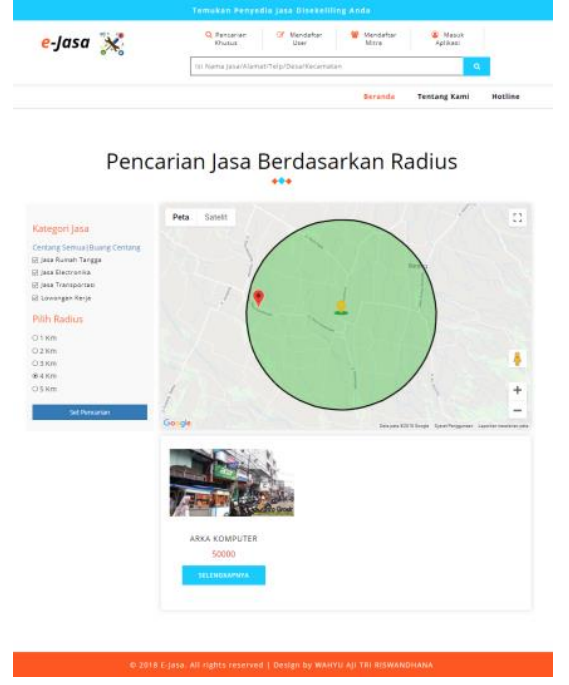

Gambar 17. Pencarian Berdasarkan Radius / Jarak

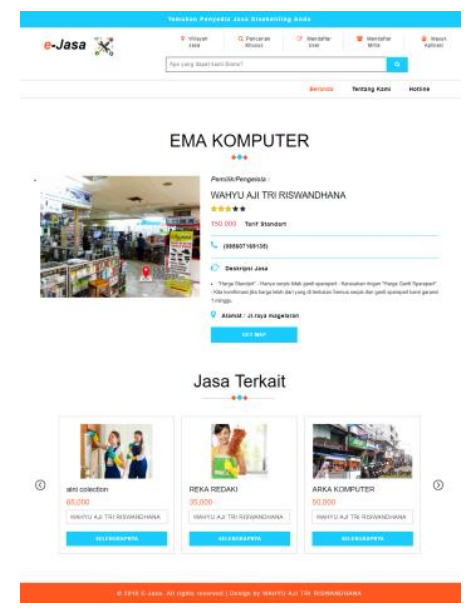

Gambar 18. Halaman Pencarian Berdasarkan Radius

\section{KESIMPULAN}

Adanya perancangan dan implementasi jasa online dapat membantu Pemesan jasa dalam mencari penyedia jasa. Sistem memberikan kemudahan kepada pemesan dalam melakukan pemesanan jasa.

Berdasarkan uraian sebelumnya maka dapat disimpulkan aplikasi ini dapat membantu masyarakat bagi yang memiliki bakat atau keahlian sehingga dengan aplikasi ini mereka bisa mendaftarkan diri mereka melalui aplikasi ini supaya bakat dan keahlian mereka bisa bermanfaat untuk mendapat pekerjaan serta membantu orang lain yang membutuhkannya.

\section{SARAN}

Pengembangan yang dapat dilakukan dari penelitian ini adalah sistem ini dapat dikembangkan untuk pembayaran secara online agar lebih aman dalam bertransaksi, dan tidak hanya orang yang mempunyai jasa yang ada dalam sistem akan tetapi juga sebagai wadah untuk info perusahaan yang membutuhkan orang untuk bekerja di kantor nya. 


\section{DAFTAR PUSTAKA}

Abdullah, Lazim and Mei Ling, Hui . 2013. Interval-valued Intuitionistic Fuzzy Weighted Entropy in Evaluation of Service Quality. Malaysia: Department of Mathematics, Faculty of Science and Technology, University Malaysia Terengganu.

Adam, Suseno. dan Ricky, Agus. 2012, Penggunaan Quantum GIS Dalam Sistem Informasi Geografis, Bogor

Agung, Aulio Romadho, Kridalukmana, Rinta dan Windasari, Ike Pertiwi. 2016. Pengembangan Sistem Informasi Pemesanan Layanan Jasa Cleaning Service Berbasis Web Dan Mobile Di Liochita Cleaning Semarang. Semarang: Program Studi Sistem Komputer, Fakultas Teknik, Universitas Diponegoro.

Herman, Erik.2016. Sistem Informasi Manajemen PT. Kapuas Jaya Anugrah. Pontianak: Universitas Tanjungpura.

Indra Yatini B. Aplikasi Pengilahan Citra Berbasis Web Menggunakan JavaScript Dan Jquery, Staf Pengajar Jurusan Teknik Informatika, STMIK AKAKOM Yogyakarta.

Jogiyanto. 2005, Analisis dan Desain Sistem Informasi: Pendekatan Struktur, Teori dan Praktik Aplikasi Bisnis, Hal 1, Andi offset, Yogyakarta.

Prahasta, Eddy. 2002, Konsep-konsep Dasar Informasi Geografis, Informatika, Bandung.

Redha, Muhammad, Tursina, Tursina dan Pratiwi, Helen Sasty. 2016. Rancang Bangun Aplikasi Webgis Penyedia Jasa Properti Online Berbasis Virtual Online Tour. Pontianak: Program Studi Informatika Universitas Tanjungpura.

Sita Laksmita, I. A. K. ,Kompiang Oka Sudana, A. A and Wira Buana, Putu. 2012. Design Webbased GIS Application for Rabies Spread in Bali Province. Bali: Departement of Electrical and Computer Engineering, Udayana University.

Trisna Dewi, Zara Rizq Azzindani Ahmadi, Candra Suardika, I Gede. 2015. Dashboard Executive Information System Pada Banjar Berbasis Web. Yogyakarta: Sekolah Tinggi Ilmu Manajemen Informatika Dan Teknik Komputer.

Yogi, Rezal Renandha Prapta. 2017. Rancang Bangun Sistem Informasi Penjualan Jasa Online. Jombang: Jurusan Teknik Informasi Universitas KH. A. Wahab Hasbullah (UNWAHA) Jombang. 